\title{
Conductive Hearing Loss and Malformed Low-set Ears, as a Possible Recessive Syndrome*
}

\author{
MARVIN C. MENGEL, BRUCE W. KONIGSMARK, CHARLES I. BERLIN $\dagger$, and \\ VICTOR A. McKUSICK
}

\begin{abstract}
From the Division of Medical Genetics, Division of Laryngology and Otology and Department of Pathology, The fohns Hopkins University School of Medicine, Baltimore, Md, U.S.A.
\end{abstract}

More than 50 phenotypically distinct forms of hereditary deafness have been found in man (Konigsmark and McKusick, 1966; Procter and Procter, 1967). On the basis of associated defects caused by the same gene, these can be separated into 10 different groups. These groups include: deafness associated with integumentary system disease (Robinson, Miller, and Bensimon, 1962), heart disease (Fraser, Froggatt, and James, 1964), skeletal disease (Forney, Robinson, and Pascoe, 1966), eye disease (Alström et al., 1959), nervous system disease (Matthews, 1950), renal disease (Braun and Bayer, 1962), thyroid disease (Batsakis and Nishiyama, 1962), external ear malformations (Fourman and Fourman, 1955; Wildervanck, 1962), as well as deafness with no associated defects, and hereditary deafness with other associations.

A Mennonite group has been found to offer an excellent opportunity for the study of some recessive hereditary diseases, for two reasons: excellent family records are available and the rate of consanguineous marriages is high.

The two interrelated families described here were found in a health survey of conservative Mennonites in Lancaster County, Pennsylvania. In Family I, 2 of 8 children were affected with malformed low-set ears and conductive hearing loss, while in Family II, 3 of 12 living sibs were similarly affected. Though two types of external ear deformities and hearing loss have been reported (Fourman and Fourman, 1955; Wildervanck, 1962), the deformities are quite different from those in the two branches of this family. The affected children recorded here probably have a heretofore undescribed type of familial

Received March 18, 1968.

* Presented at the meeting of the American Society of Human Genetics, Toronto, December 1, 1967.

† Present address: Department of Otolaryngology, Louisiana State University, School of Medicine.

Address reprint requests to: The Johns Hopkins Hospital, Baltimore, Maryland 21205 (Dr. Konigsmark). hearing loss, recessive in transmission, and characterized by malformed low-set ears with conductive hearing loss.

\section{Material and Methods}

A pedigree was obtained by information from each family and by records in the Mennonite Information Center.

Each of the affected children was tested in the Hospital's Hearing and Speech Center, with a standard testing procedure and criteria (Berlin, 1965). The battery of tests included: air conduction, bone conduction, speech reception threshold, speech discrimination and tone decay; the short-increment sensitivity index (SISI), and the alternate binaural loudness balance test were done when appropriate. In addition, all affected children had caloric vestibular tests, and physical and neurological examinations. Chromosomal analyses were done on two affected children, skull $x$-rays on two, temporal bone polytomograms on one, and an exploratory tympanotomy on one patient. Psychological testing was done on three affected children.

\section{Findings}

Ear Deformity. All six affected children showed this defect to some extent bilaterally. The pinna was small, sometimes low-set, with a large overturned skin flap at its dorsal edge. The mildest form of the deformity showed only minimally deformed pinna. However, in the most severe forms, the pinna was low-set, quite small, and half-moon in shape (Fig. 1, 2, and 3).

Mental Status. By history three of the six affected children (Fig. 4) had been slow in sitting, walking, and speaking. One (II. 1) did not walk until 5 years of age. Now, at the age of 19, he can feed and dress himself and do simple household tasks.

Intelligence tests on four of the affected (I. 1, II. 1, II. 3, II. 4; Fig. 4) placed three (I. 1, II. 1, 


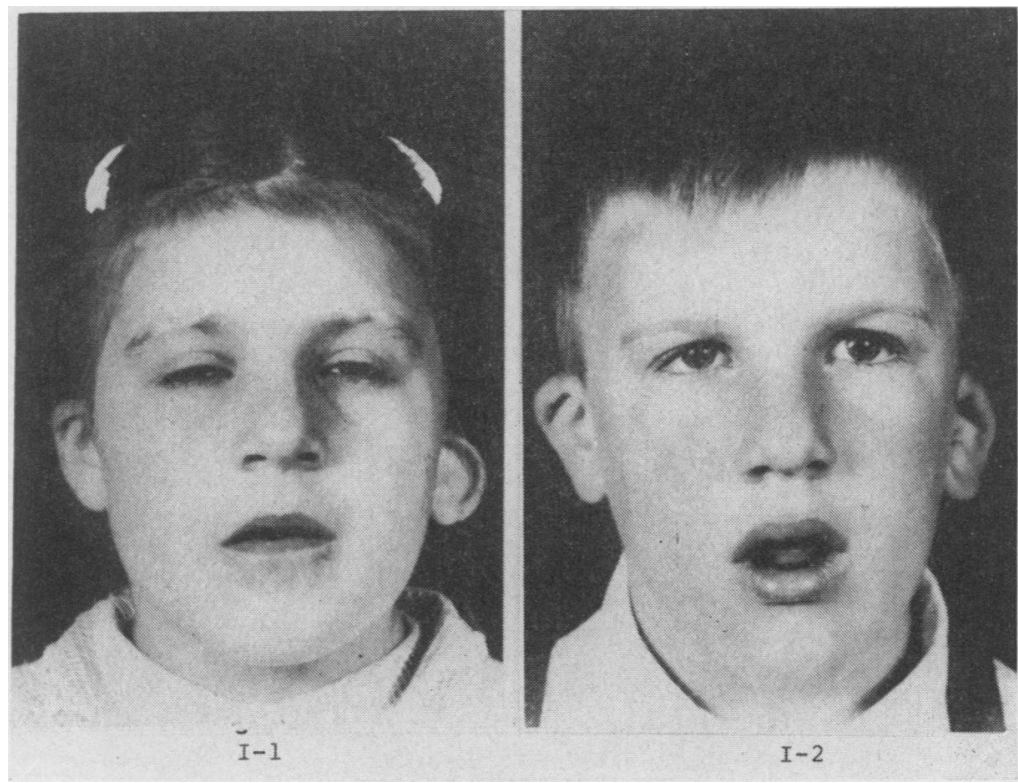

FIG. 1. The 2 affected sibs in Family I.

II. 4) in the severely retarded category, and one (II. 3) in the normal range.

Hearing. Pure tone audiograms showed four of the six affected children to have a 70 to $80 \mathrm{~dB}$ HL ISO three frequency average loss in at least one ear. Bone conduction testing showed minimally decreased hearing, indicating a conductive loss with pathology in the middle ear. SISI and recruitment tests were negative, indicating no cochlear damage. Tone decay tests were also negative, suggesting no retrocochlear pathology. Speech reception threshold scores validated the pure tone audiometry. In one patient (II. 1), we were unable to get any response to tones to $110 \mathrm{~dB}$ HL ISO. This patient was severely retarded and could not understand test instructions. Another child (II. 4) could not be tested because of low IQ, giving erratic responses at 80 to $100 \mathrm{~dB} \mathrm{HL}$.

Ossicular Chain Deformity. An exploratory tympanotomy, was performed on one (II. 2). At operation, a single ossicle was noted; this had the shape of a malleus and was somewhat posteriorly positioned. No incus was seen. A loose cord, attached to the head of the malleus, passed medially to the oval window area. Inspection of the oval window revealed no foot-plate or superstructure of the stapes present. The promontory was relatively normal, and a round window niche could not be seen. The bone in the area of the oval window was trephined, removing approximately $2 \mathrm{~mm}$. of bone, leaving in a very thin plate of bone over the vestibule. This plate was then removed, and a slight leak of perilymph noted. A No. 6 Teflon prosthesis was placed into the opening, and its wire end was attached to the neck of the malleus. The prosthesis was noted to move with the malleus when this was manipulated.

The patient was noted to have a 10 to $15 \mathrm{~dB}$ improvement in hearing on subsequent auditory tests, but because his other ear had a less severe hearing loss, this improvement was not clinically apparent.

\section{Physical and Neurological Examination}

Small Stature. Three of the six affected children were somewhat smaller than the average of their sibs for that age.

Head and Neck. In addition to the ear deformity, three of the six affected children had a high arched palate, not noted in any of their non-affected sibs. Otherwise, the head and neck examination showed no abnormalities.

Cardiovascular. Five of the six affected children had a grade 1-4/6 systolic blowing murmur heard best at the cardiac apex. None of the unaffected sibs had such a murmur. Electrocardiograms were normal showing no cardiomegaly or axis deviation. There were no symptoms of cardiovascular disease. 

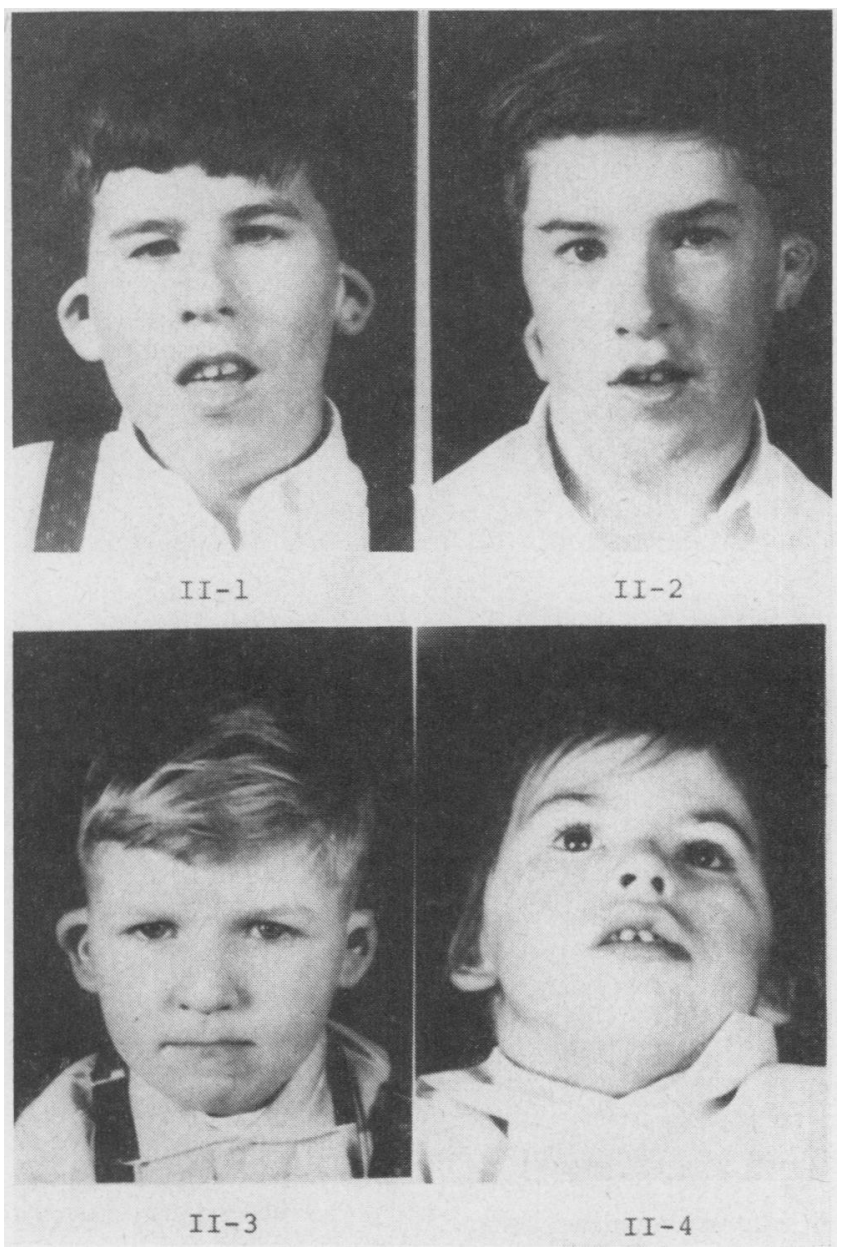

FIG. 2. The four affected sibs in Family II.

Other Findings. Two of the four affected males (I. 2 and II. 1) had cryptorchidism with no testes palpable in the scrotum or canals. These and one other (II. 2) had hypogonadism, but chromosome examinations done on two of these (I. 2 and II. 2) were normal.

The two children in Family. I had genu valgum, but this may be an independent trait since their mother had a similar appearance and none of the children in Family II were affected. These two children also showed slight clinodactyly, not seen in any of the other children.

One child (II. 1) had marked pes planus and valgus, not seen in any of the other children.

Neurological and vestibular examinations were normal in all six affected children.

\section{Case Reports}

Case 1. The proband (I. 1) was a 10-year-old girl, with one ear mildly affected and one moderately affected. She first sat up at 9 months, later than her 2 older sibs, o though she did walk at 13 months. The family grad- N ually became aware of a hearing loss, probably alerted to expect it by the deformed external ear. She spoke her first words at about 2 years of age, and could form sentences by 6 years of age. She did well in a special class in public school. Testing at her school placed her IQ in the 40 to 60 range.

On physical examination she was small for her age $(117 \mathrm{~cm} ., 22.3 \mathrm{~kg}$.), with a grade $2 / 6$ systolic ejection murmur loudest at the apex, and transmitted to the carotids. She had slight asymmetry of the mouth and bilateral genu valgus. Physical examination was otherwise normal. Audiologically, her right ear was normal; 


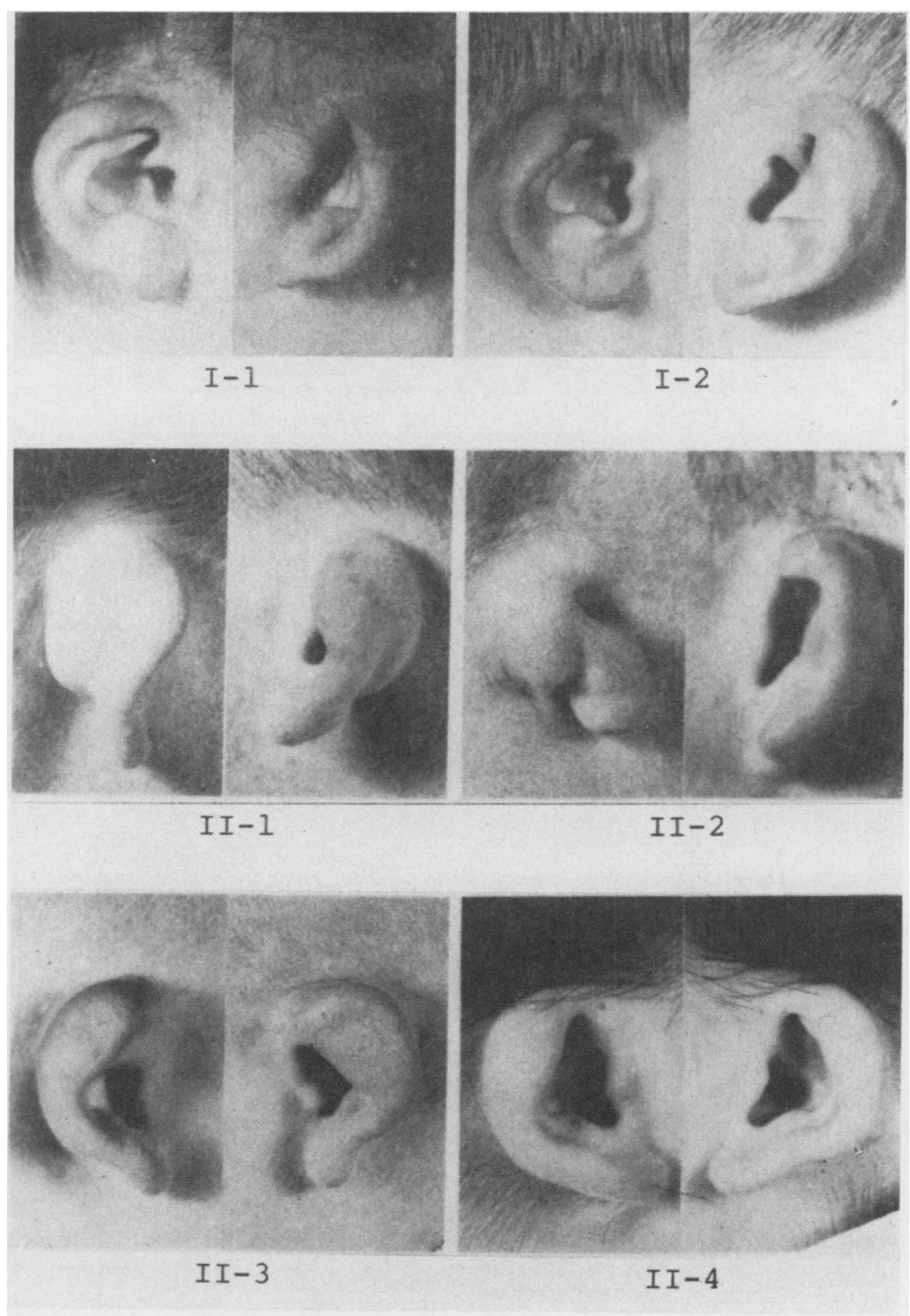

Fig. 3. Composite picture showing the external ears of all affected children. The left ear is on the left and right ear on the right in each case.

her left ear showed a conductive hearing loss of 60 to 70 dB HL ISO (Fig. 5), with 50 to $60 \mathrm{~dB}$ narrow band masking in the appropriate ear.

Case 2. I. 2, her brother, was 6 years old and had more severely affected pinnae bilaterally than his older sister. His father felt he had been slow in development, recalling only that he walked at about 14 to 16 months. He attended the local parochial school, doing fair work. He was a pleasant boy, slightly small for his age (113.6 cm., $21.3 \mathrm{~kg}$.). He did not speak sentences but understood and obeyed very well. His mental retardation was milder than that of his sister.

Physical examination showed a harsh blowing systolic murmur (Grade 4/6) loudest at the apex. His reflexes were brisk but symmetrical. He had extremely small genitalia, with well-marked mediam raphe and no testis. in his scrotum. Chrumosome cultures showed a normal karyotype. He had slight genu valgum. Audiological testing showed a severe conductive deafness bilaterally 


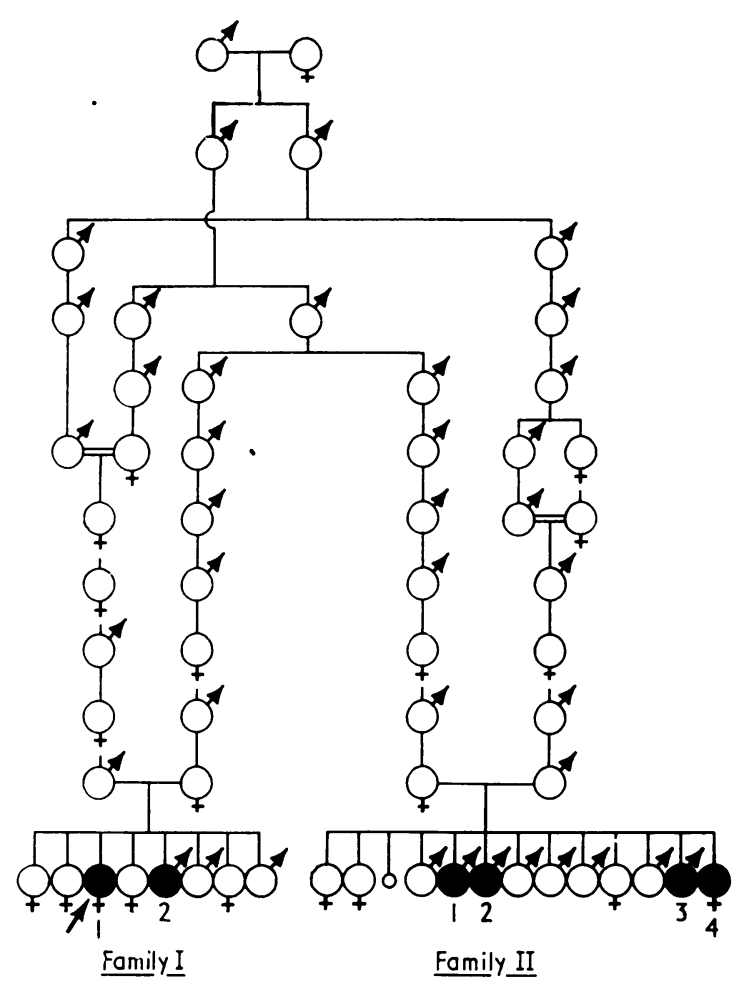

FIG. 4. Pedigree showing 2 affected sibs in Family I, and 4 affected sibs in Family II.

(Fig. 4). Conventional bone conduction results were supported by SAL observations. The SISI was negative in both ears at $4000 \mathrm{cps}$, suggesting no cochlear pathology.

Case 3. II. 1, a 19-year-old boy, was the most retarded of the six affected, being unable to walk until he was 5 years of age. He was $155 \mathrm{~cm}$. tall, and weighed $41.4 \mathrm{~kg}$. He walked with a shuffle, showing marked planus and valgus of both feet. He understood simple visual commands and obeyed them willingly. The family communicated with him non-verbally, by illustrating what they wanted him to do. They were unable to get his attention by shouting, but sometimes a loud clap caused him to turn and look. When left by himself, he sat hunched and drawn together, touching his cheek rhythmically with his finger.

He placed in the severe mental defective range on the Bender-Gestalt visual motor test, and was unable to comprehend instructions for any of the other intelligence tests attempted. Though he did not respond in any way to pure tone testing, unconditioned GSR showed a response to $100 \mathrm{~dB} \mathrm{HL}$ tone at 1000 to 4000 cps.
Case 4. II. 2, an 18-year-old brother, was $166.4 \mathrm{~cm}$. tall and weighed $56.9 \mathrm{~kg}$. He spoke poorly, probably due to poor hearing. He was able to finish the eighth grade at a parochial school in regular classes. His $\overline{\bar{n}}$ pinnae were severely affected (Fig. 2 and 3); one was 7 quite low-set.

Case 5. II. 3, a 6-year-old boy, was normal on physical, neurological, and vestibular examination except for a $2 / 6$ systolic murmur. The best two fre- $c$ quency averages in the speech range were $67 \mathrm{~dB} \mathrm{HL} \vec{\circ}$ in the left ear and $5 \mathrm{~dB} \mathrm{HL}$ in the right ear. His pinnae were mildly deformed (Fig. 2 and 3 ).

He had a mental age of 5 8/12 years with an IQ of 98 on the Stanford Binet intelligency scale Form L-M. He scored in the mental age level 3-9, with a quotient of 65 on the Peabody Picture Vocabulary Test. His vocabulary was poor relative to his normal intelligence.

Case 6. II. 4, a 5-year-old girl, had a completely normal physical, neurological, and vestibular test. She had no systolic murmur. Her language development score was below the 18-month level, with visual motor and form perception functioning in the 2- to 3-year range. Her over-all ability was in the 40 to $60 \mathrm{IQ}$ range. Though she apparently could hear well in response to verbal commands, we were unable to obtain criterion level pure tone test results with this child.

Remainder of Family. The parents in these two families were not affected with the syndrome described. In Family I, the maternal great grandfather and two paternal uncles had a hearing loss in their 5th to 6th decade of life. In Family II, the father was 46 years old and had a neural hearing loss without an air-bone gap. The paternal grandfather had a hearing loss since his 6th decade of life, and three paternal cousins were mentally retarded, one with histidinaemia.

\section{Discussion}

Syndrome. The features of this syndrome can be divided into those which appear in all affected and those which are inconstant. Features present in all affected include: (1) pinna deformity, varying greatly in degree (Fig. 1, 2, and 3), (2) conductive hearing loss, usually bilateral, and varying from mild to severe. The following features were present in only some of the affected, but probably are features of the syndrome: (a) low-set ears, present in three of the six affected; (b) mental retardation, present in three of the affected; (c) immature external genitalia, present in all affected males.

In addition to these features, five of the six affected children were smaller than their sibs. Three had a high arched palate, and five had a systolic murmur with normal electrocardiograms and 

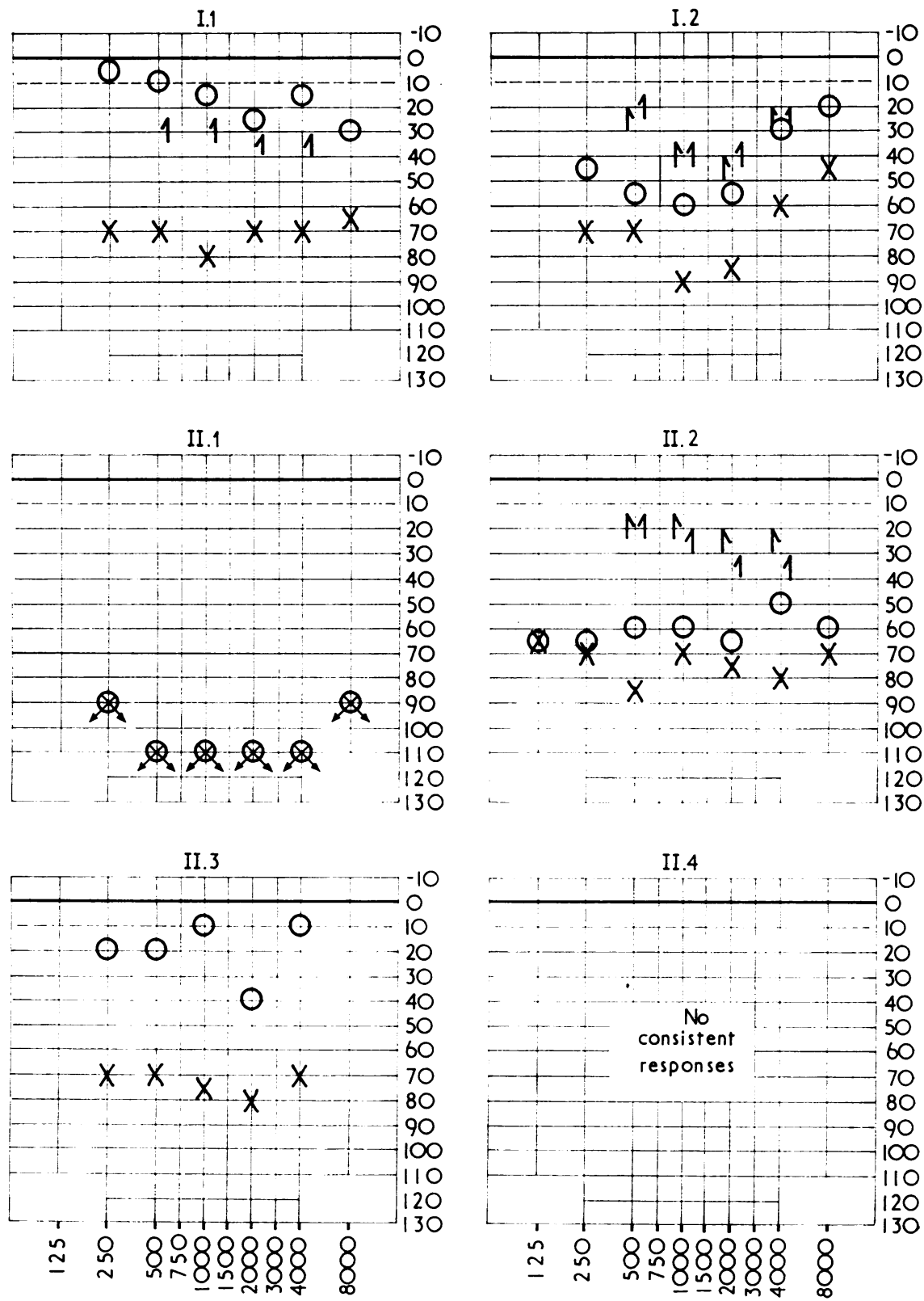

Cycles per second

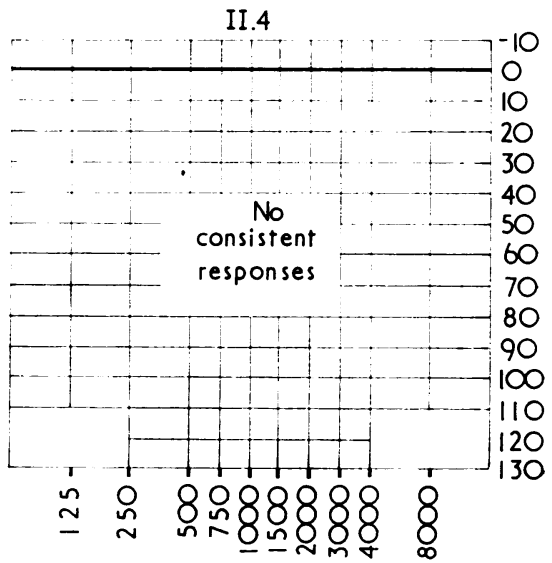

Cycles per second

Fig. 5. Audiograms of all affected children.

Air conduction

$\underset{0}{\text { Right }} \quad$ Left 
chest $x$-rays. Two of the four males had hypogonadism and all four males had immature genitalia.

Mental retardation was present in three of the six affected. The retardation was not associated with the amount of hearing loss, severity of pinna abnormalities, or any other features (Table).

Three cousins of the children of Family II were retarded, and at least one had histidinaemia. $\mathrm{Pa}-$ tient II. 3 also had a positive ferric chloride test for histidinaemia, as did both parents. The retarded child, II. 1, had a negative ferric chloride test but had a history of prolonged cyanosis immediately after birth. The third retarded child, I. 1, had a negative ferric chloride test, and no history of cyanosis or illness consistent with retardation.

There is no way of knowing the cause of the retardation; it may be part of the syndrome of ear deformity and deafness, it may be related to histidinaemia in one child, or it may be due to another rare recessive disorder.

External Ear Malformations. Three types of familial external ear malformations have been described. Potter (1937) presented five generations of a family with a pinna malformation but without hearing loss transmitted as an autosomal dominant. This deformity is somewhat similar to that in the present kindred, and best described as a small deformed, inverted pinna. None of these ears was low-set.

Fourman and Fourman (1955) described a family with pre-auricular pits and neural hearing loss. The hearing loss in our patients was conductive, and no pre-auricular pits were found. Wildervanck (1962) presented a family with dominantly transmitted conductive hearing loss associated with pre-auricular tags and malformed pinnae. In none were the ears malplaced. None of our patients had pre-auricular pits.
Origin of Hearing Loss. Audiograms on most $\vec{A}$ of the affected children indicated a conductive hear- 을 ing loss. In one patient (II. 2) the hearing loss was due to malformation of the middle ear bones, as documented at operation. Probably, middle ear malformation is responsible for the hearing loss in the remaining affected children.

Though several types of familial conductive hear- $₫$ ing loss have been described, in only mandibulofacial dysostosis has a malformation of the middle ear bone been documented (Holborow, 1961). There is little similarity between the present syndrome and the characteristic hypoplastic mandible and normal ears of Treacher Collins disease.

Type of Transmission. The family trees were traced for 12 generations. All four parents were descendants of a man who died in Switzerland in 1720. His four sons came to this country in the early 18th century. It appears that this syndrome is transmitted as a single autosomal recessive gene and was carried to this country by at least two sons of the progenitor.

Treatment. The mild improvement in hearing in one of our patients (II. 2) by insertion of a prosthesis suggests that patients with this affection $N$ deserve a complete otological and audiological study, with the aim of possible surgical correction of the hearing loss.

\section{Summary}

In a health survey of a genetic isolate, six cases of pinna deformity and conductive deafness were found. Tympanoplasty in one patient showed malformation of the middle ear bones. Other features, including mental retardation and hypogonadism, may be part of the disease. The mode of transmission is autosomal recessive. 
We wish to thank Dr. Minerva Stauffer for bringing these families to our attention.

Supported in part by Grant RD-1786 from the Vocational Rehabilitation Administration, The John A. Hartford Foundation, Inc., and NINDB Res. Career Dev. Award 5D3 NB, 19, 488.

\section{REFERENCES}

Alström, C. H., Hallgren, B., Nilsson, L. B., and Äsander, H. (1959) Retinal degeneration combined with obesity, diabetes mellitus and neurogenous deafness. Acta psychiat. scand., 34, Suppl. 129, 1.

Batsakis, J. G., and Nishiyama, R. H. (1962). Deafness with sporadic goiter: Pendred's syndrome. Arch. Otolaryng., 76, 401.

Berlin, C. I. and The Staff of the Hearing and Speech Center (1965). Manual of Standard Operating Procedures. The Johns Hopkins Medical Institutions, Baltimore.

Braun, F. C., and Bayer, J. F. (1962). Familial nephrosis associated with deafness and congenital urinary tract anomalies in siblings. f. Pediat., 60, 33.
Forney, W. R., Robinson, S. J., and Pascoe, D. J. (1966). Congenital heart disease, deafness, and skeletal malformations: A new syndrome? ibid., 68, 14 .

Fourman, P., and Fourman, J. (1955). Hereditary deafness in family with ear-pits (fistula auris congenita). Brit. med. f., 2, 1354.

Fraser, G. R., Froggatt, P., and James, T. N. (1964). Congenital deafness associated with electrocardiographic abnormalities, fainting attacks and sudden death. A recessive syndrome. Quart. $\mathcal{F}$. Med., 33, 361.

Holborow, C. A. (1961). Deafness and the Treacher Collins syndrome. F. Laryng., 75, 978.

Konigsmark, B. W., and McKusick, V. A. (1966). Hereditary deafness. Volta Rev., 68, 336.

Matthews, W. B. (1950). Familial ataxia, deaf-mutism, and muscular wasting. f. Neurol. Neurosurg. Psychiat., 13, 307.

Potter, E. L. (1937). A hereditary ear malformation transmitted through five generations. F. Hered., 28, 255.

Procter, C. A., and Procter, B. (1967). Understanding hereditary nerve deafness. Arch. Otolaryng., 85, 23.

Robinson, G. C., Miller, J. R., and Bensimon, J. R. (1962). Familial ectodermal dysplasia with sensori-neural deafness and other anomalies. Pediatrics, 30, 797.

Wildervanck, L. S. (1962). Hereditary malformations of the ear in three generations. Acta oto-laryng. (Stockh.), 54, 553. 